\title{
A fuzzy rule-based expert system to determine Propofol drug dosage in anesthesia
}

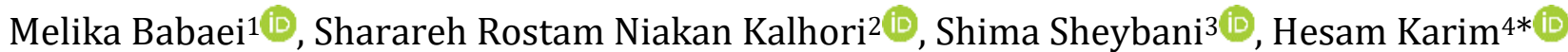 \\ ${ }^{1}$ Mashhad University of Medical Sciences, Mashhad, Iran \\ ${ }^{2}$ Associate Professor, Department of Health Information Management, School of Allied Medical Sciences, Tehran University of Medical Sciences, \\ Tehran, Iran \\ ${ }^{3}$ Assistant Professor, Faculty of Medicine, Mashhad University of Medical Sciences, Mashhad, Iran \\ ${ }^{4} \mathrm{PhD}$ in Medical Informatics, Tehran Shahre Salem Company, Tehran Municipality, Tehran, Iran
}

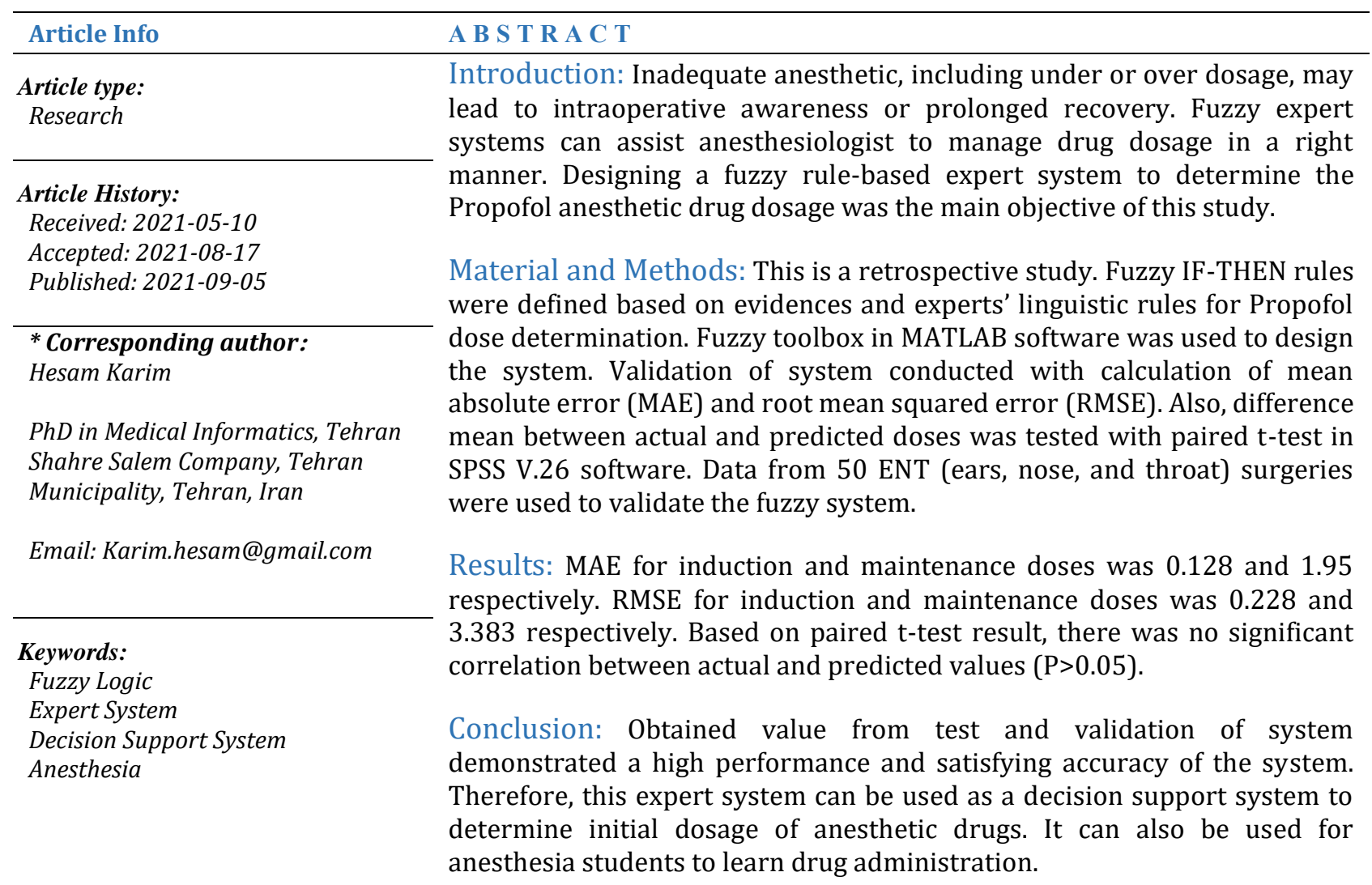

Cite this paper as:

Babaei M, Niakan Kalhori SR, Sheybani S, Karim H. A fuzzy rule-based expert system to determine Propofol drug dosage in anesthesia. Front Health Inform. 2021; 10: 89. DOI: 10.30699/fhi.v10i1.304

\section{INTRODUCTION}

Anesthesia as a part of the medical profession ensures that the patient does not respond to pain and other stimuli during surgery [1]. General anesthesia affects the brain cells and puts the patient unconscious, pain free, inactivity and free from memory [2]. Anesthesiologists have several definitions of anesthesia state []․ Many factors affected on anesthetic drugs dosage. To determine the appropriate dose of anesthetic drug, anesthesiologists make decisions about the patient's level of consciousness based on personal experiences and measuring physiological parameters such as cardiac factors, blood pressure [4- $\underline{8}]$. It is difficult to pay attention to all parameters simultaneously and an anesthesiologists cannot focus on all physiological factors together [1]. Furthermore, uncertainty in some factors that represented by linguistic variables, make it more difficult to calculate the dose of drug [9]

While the patient may be revive in the middle of surgery due to low level of anesthetic, patient anesthesia for a long time may lead to mortality [1]. Additionally, human errors in anesthesia account for more than $80 \%$ of the preventable mishaps [10]. Therefore, accurate and non-invasive monitoring of the depth of anesthesia is highly desirable [11]; this is a challenge to determine the appropriate dose by anesthesiologists [1]].

Recently, along with intelligent systems development, computational intelligence has been used to solve many complex problems [12]. There has been a rapid growth in patient monitoring and 
medical data analysis using intelligent decision support systems (DSS) based on expert systems, fuzzy logic, and other techniques. Since the past decade, it has been proved that fuzzy logic is useful for intelligent system designing in medicine. In order to improve the physician's performance by imitating human thought processes in complicated situations where humans are inappropriate, it has been shown that fuzzy logic-based expert systems are appropriate in medical applications [13] .

In determination of anesthetic dose, there are some uncertain factors. For instance, anesthesiologists define age of patient in a set of groups such as pediatric, elderly and adult. This makes it difficult to calculate drug dose based on age. Hence, in this study we utilized fuzzy sets for defining the input variables and an intelligent system based on fuzzy logic can help anesthesiologist for calculate the dose of anesthetic [14]. The aim of this study was to design a fuzzy rule-based expert system for determining the induction and maintenance doses of Propofol as an anesthetic drug.

\section{Fuzzy Logic}

Fuzzy logic is a soft computing technique which has developed to recreate human learning and logical decision in an uncertain environment. This logic enables users to descript the system's behavior with natural language thorough linguistic variables. However, this tool makes it possible to create a structure for expert's behavior representation [15]. In this structure, human's decisions will be descripted through collection of IF-THEN rules which makes association between input factors and final decisions [16].

Fuzzy inference system consists of four main parts as follows: 1) Fuzzification which converts the crisp value of inputs into linguistic values, 2) Inference engine which includes mechanism of fuzzy inference to output obtaining, 3) Defuzzification which converts the output of fuzzy inferences into crisp values, 4) Knowledge base which contains membership functions and fuzzy rules that organized into database and rule based, respectively. However, choosing the right rules, membership functions and parameters of fuzzy inference system play crucial role to achieve the right model [17].

\section{General anesthesia and Propofol}

General anesthesia is a medical condition of unconsciousness with loss of protective reflexes, resulting from the administration of one or more general anesthetic agents. It is carried out to allow medical procedures that would otherwise be intolerably painful for the patient, or where the nature of the procedure itself precludes the patient being awake $[\underline{18}, \underline{19}]$.
Induction is a term that refers to the first stage of anesthesia, prior to reach a depth suitable for surgery. The speed of induction depends on the time taken for the drug to reach an effective concentration in the brain. During this stage, the patient progresses from analgesia without amnesia to analgesia with amnesia. Patients can carry on a conversation at this time. The duration of action of intravenous induction agents is generally 5 to 10 minutes, after which spontaneous recovery of consciousness will occur. In order to prolong unconsciousness for the required duration of surgery, anesthesia must be maintained. This is achieved by administering medication like Propofol. The units of induction and maintenance doses are calculated based on $\mathrm{mg} / \mathrm{kg}$ and $\mu \mathrm{g} / \mathrm{kg} / \mathrm{min}$, respectively. The basic dose of each anesthetic drug is measured by $\mathrm{mg}(\mathrm{mlg})$ and it will be changed based on patient's weight [19].

Propofol is probably the most frequently administered anesthetic drug for induction of anesthesia. In addition, Propofol is used during maintenance of anesthesia and is a common selection for sedation in the operating room as well as in intensive care unit. Advantages of this drug are rapid induction in general anesthesia, rapid return of consciousness, minimal effects on the central nervous system (CNS), and reduction of postoperative nausea and vomit $[\underline{18}, \underline{20}, \underline{21}]$; therefore, in this study we used Propofol dosage information.

\section{MATERIAL AND METHODS}

\section{System design and development}

In this retrospective study, in order to determine Propofol dosage information, we collected linguistic rules for Propofol dosage from references such as anesthesia books [18, 19] and anesthesia dosing information [22]. In addition, we recorded expert's knowledge with interview sessions. The expert's information is shown in Table 1.

Table 1: Expert's information

\begin{tabular}{|l|l|l|l|l|}
\hline No. & Specialty & $\begin{array}{l}\text { Age } \\
\text { (year) }\end{array}$ & Gender & Workplace \\
\hline 1 & Anesthesiologist & 45 & Male & $\begin{array}{l}\text { Ghaem } \\
\text { Hospital, } \\
\text { Mashhad }\end{array}$ \\
\hline 2 & Anesthesiologist & 38 & Female & $\begin{array}{l}\text { Ghaem } \\
\text { Hospital, } \\
\text { Mashhad }\end{array}$ \\
\hline 3 & $\begin{array}{l}\text { Nurse } \\
\text { Anesthetist }\end{array}$ & 40 & Male & $\begin{array}{l}\text { Ghaem } \\
\text { Hospital, } \\
\text { Mashhad }\end{array}$ \\
\hline
\end{tabular}

All obtained rules were analyzed to identify input variables and produce the final rules for fuzzy system. Age, weight and blood pressure were considered as input factors. Cardiovascular and neurological 
diseases were considered as comorbidities. Also, we considered the use of Remifentanil as an anesthetic drug along with Propofol in input variables. Usage of this drug leads to lower maintenance doses. Output variables in this study were induction and maintenance doses.

Based on the input/output variables and specified rules, we designed fuzzy model with appropriate membership functions for each parameters as fuzzy sets. Afterwards, we defined fuzzy IF-THEN rules. "Mamdani" fuzzy inference system was used for defining membership functions and rule base development. Every rule consists of two parts. Premise part of the rule operates in fuzzy subspace of inputs while consequent part describes the output within the fuzzy subspace of output. Defuzzification was done using 'Centroid Rule'. A graphical user interface was designed to provide a comfortable environment for users. All processes of system development were conducted using fuzzy logic toolbox in MATLAB R2010 software.

\section{System test and validation}

Data from 50 ENT (ears, nose, and throat) surgeries at Ghaem hospital in Mashhad, Iran were applied to validate designed system. Propofol and Remifentanil were used for patients' anesthesia. These data were gathered in two months, from March to April 2020. We used data from ENT ward because this data was available at that time.

Fuzzy rule based system was validated via comparing predicted and actual dose of Propofol using mean absolute error (MAE) and root mean squared error (RMSE) calculation. These measurements are used to assess how close prediction values are to the actual values and are given by flowing equations 1and 2:

$M A E=\frac{\sum_{i}^{n}\left|e_{i}\right|}{n}$

$R M S E=\sqrt{\frac{\sum_{i}^{n} e_{i}^{2}}{n}}$

In these equations, " $n$ " is the number of surgeries that Propofol was used and "ei" is the difference between predicted and actual dose for Propofol delivering. According to the experts' view, the maximum acceptable error (difference between predicted and actual value) for induction dose is $0.5 \mathrm{mg} / \mathrm{Kg}$. Therefore, if MAE is less than 0.5 , system's output will be acceptable. Also, the maximum acceptable error for maintenance dose is $5 \mathrm{mg} / \mathrm{Kg}$. t-test was used to compare mean of actual and predicted values. All statistical calculations were conducted in statistical analysis software, SPSS 2015.

\section{RESULTS}

Based on Propofol dosage information, four factors including age, weight, cardiovascular and neurological diseases are used in induction and maintenance doses determination. Experts determine induction and maintenance doses based on blood pressure (BP) and Remifentanil usage in addition to those factors. We extracted the fuzzy IFTHEN rules base on both evidences and experts' rules. Table 2 shows initial and final rules for dose determination.

Fuzzy model developed for Propofol dose determination showed in Fig 1. This fuzzy model has four input variables including: age, blood pressure, cardiovascular disease, and neurosurgical disease and two output variables including: induction and maintenance. Weight and Remifentanil variables were used in induction and maintenance dose calculation for each patient; thus, it not considered as an input variable in fuzzy model.

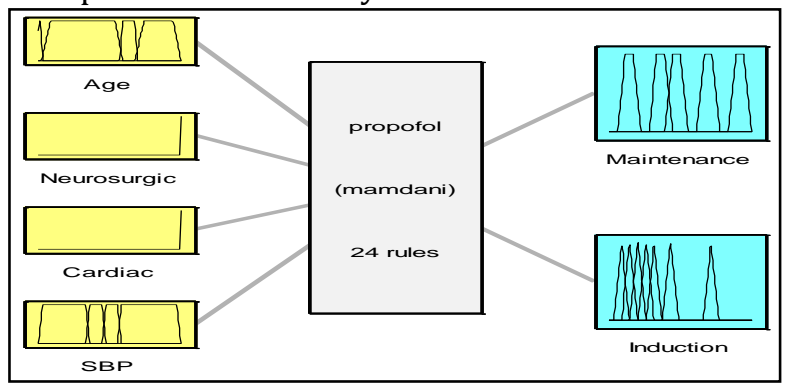

Fig 1: Fuzzy Model with four inputs and two outputs variables

Membership functions for each input variable are shown in Fig 2. Based on linguistic rules, age was categorized into 4 ranges contains pediatrics (under 16 years), adult (under 60 years), elderly (up to 80 years) and old (more than 80 years). As the same way, BP categorized into four groups contains low (under 80), ideal (80-100), pre-high (100-120) and high (more than 120). The membership functions of cardiovascular disease and neurosurgical patients have just two conditions (yes or no) as these variables are binary. Membership functions for induction and maintenance doses as output variables were addressed in Fig 3. Based on linguistic rules, induction doses raged from 0.5 to 3.5 . Therefore, induction dose divided into 6 groups with a distance of 0.5. Each membership function named with " $\mathrm{I}_{\mathrm{n}}$ " that " $n$ " is the membership function's number. In the same way, maintenance dose was divided into five groups and each membership function named with " $\mathrm{M}_{\mathrm{n}}$ ". Weight and Remifentanil usage variables were used just in final doses calculation; thus, we did not consider these variables in fuzzy model. 
Table 2: Fuzzy IF-THEN rules based on evidence and experst's linguistic rules for Propofol dosage

\begin{tabular}{|c|c|c|}
\hline Fuzzy & pert's rules & uideline's rules \\
\hline $\begin{array}{l}\text { If (Age is Adult) and (BP is Pre-High) then } \\
\text { (Maintenance is M4)(Induction is I6) } \\
\text { If (Age is Adult) and (BP is High) then (Maintenance } \\
\text { is M5)(Induction is I6) } \\
\text { If (Age is Adult) and (BP is Ideal) then } \\
\text { (Maintenance is M4)(Induction is I5) } \\
\text { If (Age is Adult) and (BP is Low) then (Maintenance } \\
\text { is M3)(Induction is I2) } \\
\text { If (Age is Elderly) and (BP is Pre-High) then } \\
\text { (Maintenance is M2)(Induction is I4) } \\
\text { If (Age is Elderly) and (BP is High) then } \\
\text { (Maintenance is M3)(Induction is I4) } \\
\text { If (Age is Elderly) and (BP is Ideal) then } \\
\text { (Maintenance is M2)(Induction is I3) } \\
\text { If (Age is Elderly) and (BP is Low) then } \\
\text { (Maintenance is M1)(Induction is I2) } \\
\text { If (Age is Old) and (BP is Pre-High) then } \\
\text { (Maintenance is M2)(Induction is I3) } \\
\text { If (Age is Old) and (BP is High) then (Maintenance i } \\
\text { M3)(Induction is I3) } \\
\text { If (Age is Old) and (BP is Ideal) then (Maintenance } \\
\text { is M2)(Induction is I2) } \\
\text { If (Age is Low) and (BP is Low) then (Maintenance } \\
\text { is M1)(Induction is I1) } \\
\text { If (Age is Pediatric) and (BP is Pre-High) then } \\
\text { (Maintenance is M4)(Induction is I6) } \\
\text { If (Age is Pediatric) and (BP is High) then } \\
\text { (Maintenance is M5)(Induction is I6) } \\
\text { If (Age is Pediatric) and (BP is Ideal) then } \\
\text { (Maintenance is M4)(Induction is I4) } \\
\text { If (Age is Pediatric) and (BP is Low) then } \\
\text { (Maintenance is M3)(Induction is I3) } \\
\text { If (Cardiac is yes) and (BP is Pre-High) then } \\
\text { (Maintenance is M2)(Induction is I4) } \\
\text { If (Cardiac is yes) and (BP is High) then } \\
\text { (Maintenance is M3)(Induction is I4) } \\
\text { If (Cardiac is yes) and (BP is Ideal) then } \\
\text { (Maintenance is M2)(Induction is I3) } \\
\text { If (Cardiac is yes) and (BP is Low) then } \\
\text { (Maintenance is M1)(Induction is I2) } \\
\text { If (Neurologic is yes) and (BP is Pre-High) then } \\
\text { (Maintenance is M4)(Induction is I5) } \\
\text { If (Neurologic is yes) and (BP is High) then } \\
\text { (Maintenance is M5)(Induction is I5) } \\
\text { If (Neurologic is yes) and (BP is Ideal) then } \\
\text { (Maintenance is M4)(Induction is I4) } \\
\text { If (Neurologic is yes) and (BP is Low) then } \\
\text { (Maintenance is M3)(Induction is I2) } \\
\text { (M) }\end{array}$ & 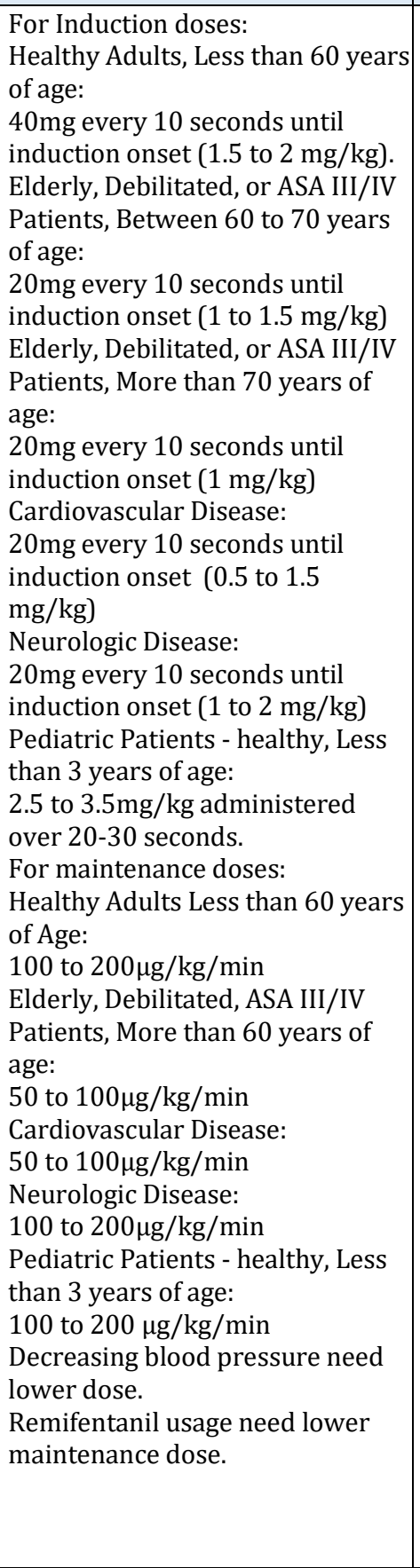 & $\begin{array}{l}\text { Patients: } \\
20 \text { mg every } 10 \text { seconds until } \\
\text { induction onset (1 to } 1.5 \mathrm{mg} / \mathrm{kg} \text { ) } \\
\text { Cardiovascular Disease: } \\
20 \text { mg every } 10 \text { seconds until } \\
\text { induction onset ( } 0.5 \text { to } 1.5 \mathrm{mg} / \mathrm{kg} \text { ) } \\
\text { NeurologicDisease: } \\
20 \mathrm{mg} \text { every } 10 \text { seconds until } \\
\text { induction onset (1 to } 2 \mathrm{mg} / \mathrm{kg} \text { ) } \\
\text { Pediatric Patients - healthy, from } 3 \\
\text { years to } 16 \text { years of age: } \\
2.5 \text { to } 3.5 \mathrm{mg} / \mathrm{kg} \text { administered over } \\
20-30 \text { seconds. } \\
\text { For maintenance doses: } \\
\text { Healthy Adults Less Than } 55 \text { Years } \\
\text { of Age: } \\
100 \text { to } 200 \mu \mathrm{gg} / \mathrm{kg} / \mathrm{min} \text { ( } 6 \text { to } 12 \\
\text { mg/kg/h) } \\
\text { Elderly, Debilitated, ASA III/IV } \\
\text { Patients: } \\
50 \text { to } 100 \mu \mathrm{g} / \mathrm{kg} / \mathrm{min} \text { (3 to } 6 \\
\text { mg/kg/h) } \\
\text { Cardiac Anesthesia: Most patients } \\
\text { require: } \\
\text { Primary DIPRIVAN Injectable } \\
\text { Emulsion with Secondary Opioid - } \\
100 \text { - } 150 \mu \mathrm{g} / \mathrm{kg} / \mathrm{min} \\
\text { Low-dose DIPRIVAN Injectable } \\
\text { Emulsion with Primary Opioid - } 50 \text { - } \\
100 \mu \mathrm{g} / \mathrm{kg} / \mathrm{min} \\
\text { Neurosurgical Patients: } 100 \text { to } 200 \\
\mu \mathrm{g} / \mathrm{kg} / \mathrm{min}(6 \text { to } 12 \text { mg/kg/h) } \\
\text { Pediatric Patients- healthy, from } 2 \\
\text { months of age to } 16 \text { years of age: } \\
125 \text { to } 300 \mu \mathrm{gg} / \mathrm{kg} / \mathrm{min} \text { ( } 7.5 \text { to } 18 \\
\text { mg/kg/h) } \\
\text { Increasing age, reduced } \\
\text { cardiovascular reserve required } \\
\text { induction dose, whereas children } \\
\text { need larger doses ( } 2.5 \text { to } 3.5 \mathrm{mg} / \mathrm{kg} \\
\text { IV). }\end{array}$ \\
\hline
\end{tabular}

* BP: Blood pressure, M: Maintenance dose, I: Induction dose

The obtained values for MAE and RMSE are presented in Table 3. MAE for induction and maintenance doses is 0.128 and 1.95 , respectively; whereas, RMSE for same doses is 0.228 and 3.383, respectively. Result of paired t-test proved there is no significant difference between the predicted and actual outputs ( $\mathrm{P}$-value $>0.05$ ).

\section{DISCUSSION}

In this study, we designed a rule-based expert system to determine the induction and maintenance dose of
Propofol for general anesthesia. The fuzzy model demonstrates good performance to predict induction and maintenance doses. The obtained value for MAE were $0.128(\mathrm{mg} / \mathrm{kg})$ and $1.95(\mu \mathrm{g} / \mathrm{kg} / \mathrm{min})$ for induction and maintenance doses. These values present the slight difference between predicted and actual doses. Based on experts 'view, a threshold of $\pm 0.5 \mathrm{mg} / \mathrm{Kg}$ is acceptable for induction dose determination. Also, for maintenance dose, it can be possible to define dose with $\pm 5 \mathrm{mg} / \mathrm{kg} / \mathrm{min}$ tolerance. Therefore, designed fuzzy system in this study works accurately and is reliable. 
Table 3: The result of system validation using MAE and RMSE as assessment measurement

\begin{tabular}{|l|l|l|l|}
\hline Variables & MAE & RMSE & P-value \\
\hline Induction dose & 0.128 & 0.228 & 0.429 \\
\hline Maintenance dose & 1.95 & 3.383 & 0.665 \\
\hline
\end{tabular}

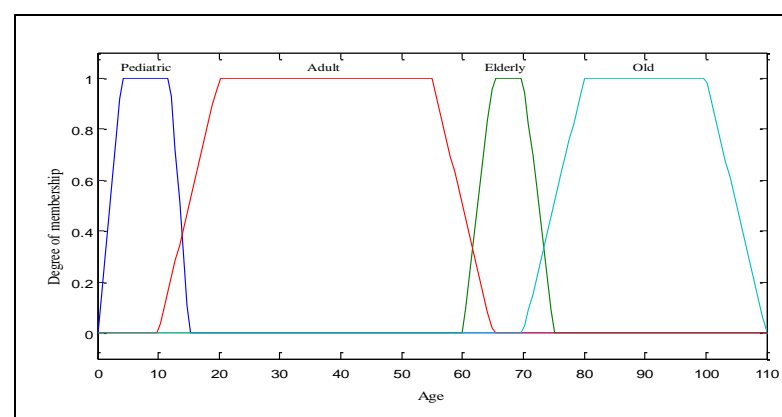

(a)

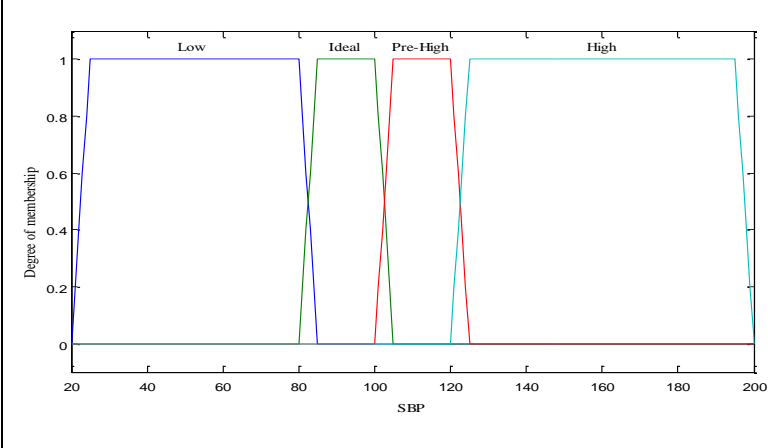

(b)

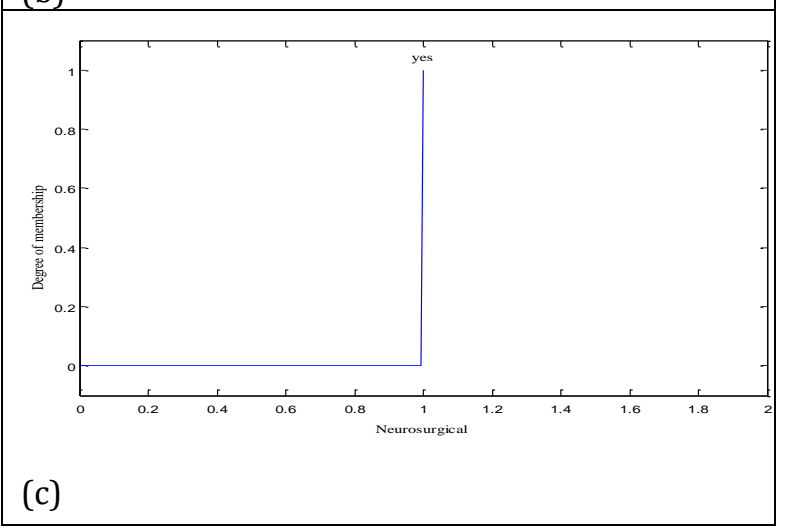

Fig 2: Membership function for input variables; Age (a), Blood pressure (b) , Neurological disease (c).

In general anesthesia, inappropriate anesthetic delivery may cause severe consequences during and after a surgery. Delivery of anesthetic agent during surgery is manually controlled by anesthetists traditionally. The first step involves the selection of an appropriate drug and dosage level according to patient weight and age and the type of surgical operation [23]. However, the human error of anesthesiologist during a surgical activity related to excessive or unbalanced amount of drug can be dangerous or even life-threatening to the patient $[\underline{7}$, $\underline{23}$ ].

Some criteria for decision about drug dose are ambiguous and based on linguistic rules. For example, for Propofol administration, increasing age and reduced cardiovascular reserve reduces the required induction dose, whereas children need larger doses [18]. In these sentences there are some linguistic variables such as "increasing age" and "reduced cardiovascular disease". Due to the human error, it can be difficult to define and decision about drug doses base on this linguistic rule. Therefore, there is a need for intelligent systems that can handle the unpredictable and imprecise variables [23]. Such an intelligent systems which use databases of expert knowledge and linguistic rules to offer advice or make decisions called expert system [24]. In order to design expert systems, knowledge engineering and having a knowledge-base is required. However, an expert system represents human knowledge engaged with uncertainty [9].Therefore, the use of expert systems in medicine is desired due to uncertainty in various cases like anesthesia.

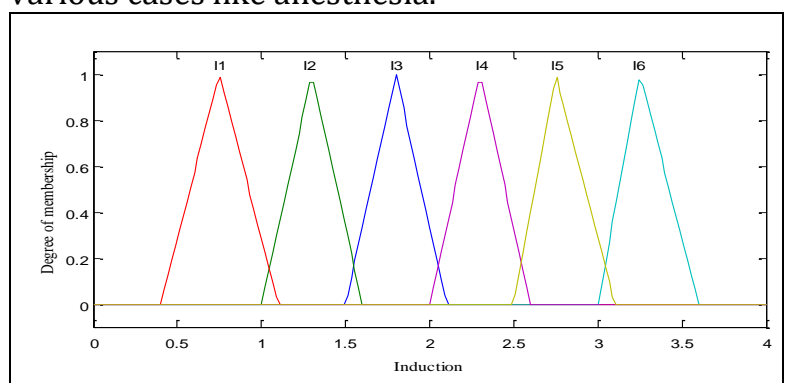

(a)

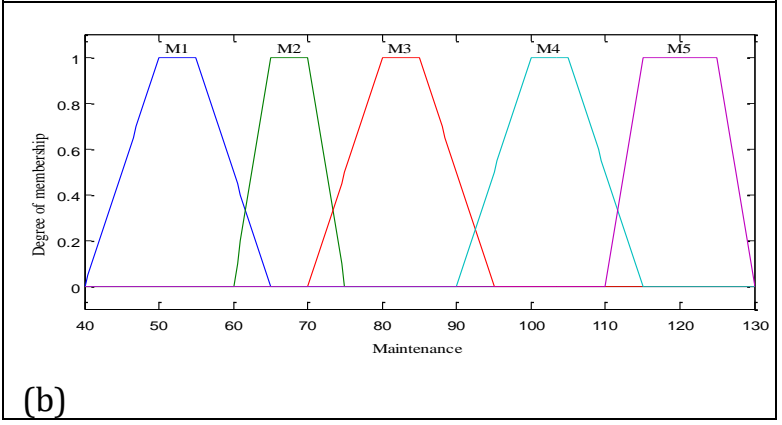

Fig 3: Membership function for output variables; Induction dose (a) and Maintenance dose (b).

One of the challenges in surgery is monitoring the patients' depth of general anesthesia. Accurate assessment of the depth of anesthesia contributes to tailor drug administration to the individual patient [7]. Thus, most of the studies designed a system to determine the depth of anesthesia based on fuzzy logic $[\underline{25}, \underline{26}]$ or neural network [27]. Yardimic et al. designed a fuzzy logic controller to control depth of sevofluorane anethesia, which was taken as a measure of the systolic blood pressure and heart rate. They collected data from 40 ASA I-II patients, who underwent an arthroscopy operation, and who were administered Sevofluorane [드] . Another study was conducted to design a fuzzy rule based system which integrates electroencephalogram (EEG) features to 
quantitatively estimate the depth of anesthesia. In that study, data from 22 patients was used to construct subsets of reference data corresponding to four well-defined anesthetic states: awake, moderate anesthesia, surgical anesthesia and isoelectric. The fuzzy rule-base index (FRI) is derived between 0 (isoelectric) to 100 (fully awake) using fuzzy inference engine and designed output MFs, accuracy of the model was $96.75 \%$ [26]. The number of studies that provide accurate induction/maintenance dose is rare. Kumar et al. propose a fuzzy model for deciding induction dose based on patient data (age, gender, height and weight) and computes the dose by defining IF-THEN rules between age and body surface area [28]. Deviation of predicted initial anesthetic dose from the actual dose given by the anesthetist to patients $(n=9)$ was found to be within $\pm 7 \%$. The validation of our system, demonstrated the best result from this previous study [28]. Also, we used more data $(n=50)$ than the other researches $[\underline{2}$, $\underline{26}, \underline{28}$ ]. Another advantage of our system is the maintenance dose calculation in addition to induction dose. However, we used just six input variables to design expert system. It is suggested to utilize more variables such as body surface area, gender and height in further studies. We used data from only ENT ward. It can lead to better results if we use more data from other wards and different patients. Besides, the expert system can be more useful if provide dose determination for other anesthetic drugs too.

\section{CONCLUSION}

In this study, a fuzzy rule-based expert system to determine the induction and maintenance dose of Propofol is proposed. This knowledge-based expert system can be used as a decision support system for anesthesiologists to determine drug doses. Moreover, the proposed system is a good tool for beginners and anesthesia students to learning anesthetic drug administration.

\section{AUTHOR'S CONTRIBUTION}

All authors contributed to the literature review, design, data collection and analysis, drafting the manuscript, read and approved the final manuscript.

\section{CONFLICTS OF INTEREST}

The authors declare no conflicts of interest regarding the publication of this study.

\section{FINANCIAL DISCLOSURE}

No financial interests related to the material of this manuscript have been declared.

\section{REFERENCES}

1. Diwase DS, Jasutkar RW. Expert controller for estimating dose of Isoflurane. International Journal of Advanced Engineering Sciences and Technologies. 2011; 9(2): 218-21.

2. Kashipara HT, Bhatt TV. Fuzzy modeling and simulation for regulating the dose of anesthesia. International Conference on Control, Automation, Communication and Energy Conservation. IEEE; 2009.

3. Lan J-Y, Abbod M, Yeh R-G, Fan S, Shieh J. Review: Intelligent modeling and control in anesthesia. Journal of Medical and Biological Engineering. 2012; 32(5): 293-308.

4. Hasani V, Farhadi M, Mirsadraee A. A comparative study of the effect of paracetamol and remifentanil on the depth of BIS-guided anesthesia in endoscopic sinus surgery. Razi Journal of Medical Sciences. 2007; 13(53): 67-72.

5. Zoughi T, Boostani R. Proposing the new methods to determine depth of anesthesia. Journal of Control. 2011; 4(4): 39-50.

6. Kalili GR, Sajedi P, Afsharyzadeh F. Depth of anesthesia determination by using bispectral index in patients underwent inhalation or total intravenous general anesthesia. Journal of Isfahan Medical School. 2008; 25(86): 78-80.

7. Musizza B, Ribaric S. Monitoring the depth of anaesthesia. Sensors (Basel). 2010; 10(12): 10896935. PMID: 22163504 DOI: 10.3390/s101210896 [PubMed]

8. Vinogradov VL, Likhvantsev VV, Subbotin VV, Larionov II, Petrov OV, Dulub VG. Bispectral index (BIS)--a new ideology in solving an old problem. Anesteziol Reanimatol. 2002; 1: 49-53. PMID: 11998389 [PubMed]

9. Zarandi MF, Zolnoori M, Moin M, Heidarnejad H. A fuzzy rule-based expert system for diagnosing asthma. Scientia Iranica. 2010; 17(2): 129-42.

10. Baig MM, Gholamhosseini H, Harrison MJ. Fuzzy logic based smart anaesthesia monitoring system in the operation theatre. WSEAS Transactions on Circuits and Systems archive. 2012; 11: 21-32.

11. Shalbaf A, Saffar M, Sleigh JW, Shalbaf R. Monitoring the depth of anesthesia using a new adaptive neurofuzzy system. IEEE Journal of Biomedical and Health Informatics. 2018; 22(3): 671- 7.

12. Phuong NH, Kreinovich V. Fuzzy logic and its applications in medicine. Int J Med Inform. 2001; 62(2-3): 165-73. PMID: 11470619 DOI: 10.1016/s1386-5056(01)00160-5 [ubMed]

13. Mirza M, Gholamhosseini H, Harrison MJ, editors. A fuzzy logic-based system for anaesthesia monitoring. Annu Int Conf IEEE Eng Med Biol Soc. 2010; 2010: 3974-7. $\quad$ PMID: 21097272 DOI: 10.1109/IEMBS.2010.5627987 [PubMed]

14. Esmaeili V, Assareh A, Shamsollahi MB, Moradi MH, 
Arefian NM. Estimating the depth of anesthesia using fuzzy soft computation applied to EEG features. Intelligent Data Analysis. 2008; 12(4): 393-407.

15. Zadeh LA. Fuzzy sets. Information and Control. 1965; 8(3): 338-53.

16. Zadeh LA. Fuzzy sets, neural networks, and soft computing. Communications of the ACM. 1994; 37(3): 77-84.

17. Qaempanah Z, Arab-Alibeik H, Ghazi Saeedi M, SadrAmeli MA. A decision support system for boosting warfarin maintenance dose using fuzzy logic. Tehran University Medical Journal. 2015; 73(4): 271-80.

18. Miller RD, Pardo M. Basics of anesthesia. $6^{\text {th }}$ ed. Elsevier Health Sciences; 2012.

19. Miller RD, Eriksson LI, Fleisher LA, Wiener-Kronish JP, Cohen NH, Young WL. Miller's anesthesia. $8^{\text {th }}$ ed. Elsevier Health Sciences; 2014.

20. Eger EI. Characteristics of anesthetic agents used for induction and maintenance of general anesthesia. Am J Health Syst Pharm. 2004; 61(Suppl 4): S3-10. PMID: 15532143 DOI: 10.1093/ajhp/61.suppl_4.S3 [PubMed]

21. Linkens DA, Abbod MF, Backory JK, Shieh JS. Closedloop control of anaesthesia using fuzzy logic. In: Szczepaniak PS, Lisboa PJG, Kacprzyk J (eds.). Fuzzy systems in medicine. Physica-Verlag HD; 2000.

22. Durbin K. Propofol [Internet]. 2017 [cited: 15 Mar 2021].

Available https://www.drugs.com/propofol.html

23. Ilyas M, Butt MFU, Bilal M, Mahmood K, Khaqan A, Riaz RA. A review of modern control strategies for clinical evaluation of Propofol anesthesia administration employing hypnosis level regulation. Biomed Res Int. 2017; 2017: 7432310. PMID: 28466018 DOI: 10.1155/2017/7432310 [PubMed]

24. O'Keefe RM, Balci O, Smith EP. Validation of expert system performance.Virginia Tech; 1986.

25. Yardimci A, Ferikoglu A, Hadimioglu N, editors. Depth control of sevofluorane anesthesia with microcontroller based fuzzy logic system. Annual International Conference of the IEEE Engineering in Medicine and Biology Society. IEEE; 2001.

26. Esmaeili V, Assareh A, Shamsollahi MB, Moradi MH, Arefian NM. Designing a fuzzy rule based system to estimate depth of anesthesia. IEEE Symposium on Computational Intelligence and Data Mining. IEEE; 2007.

27. Rabbani H, Mehri Dehnavi A, Ghanatbari M. Estimation the depth of anesthesia by the use of artificial neural network. In: Suzuki K (ed.). Artificial neural networks: Methodological advances and biomedical applications. INTECH Open Access Publisher; 2011.

28. Kumar A, Anand S, Yaddanapudi LN. Fuzzy model for estimating induction dose for general anesthesia. Journal of Scientific \& Industrial Research. 2006; 65: 325-8. 